\title{
A CHEMICAL STUDY OF MUCIN IN FIBROCYSTIC DISEASE OF THE PANCREAS
}

\author{
BY \\ CHARLOTTE ANDERSON and MAVIS FREEMAN \\ From the Clinical Research Unit, Royal Children's Hospital, Melbourne, Australia
}

(RECEIVED FOR PUBLICATION NOVEMBER 22, 1955)

The aetiology of the condition fibrocystic disease of the pancreas is still unknown, but it is considered likely that the pathological changes are brought about because the mucus produced is more viscid than normal.

Farber, Shwachman and Maddock (1943) were the first to observe that the fluid obtained from the duodenum of cases of fibrocystic disease of the pancreas was scanty and viscid, and said that the gross appearance of the material had its counterpart in the histological appearance of inspissated material in the acini and ducts of the pancreas. They also found that the mucous glands throughout the respiratory and alimentary tracts were distended and filled with inspissated material similar to that of the pancreas. On this evidence they postulated that an altered secretion from the mucous glands was the basis of this disorder. Two possible causes for this alteration were suggested: first, deficiency of mucus, and secondly, excess of vagal activity, the latter being due to autonomic imbalance in the control of mucous gland secretions. No further evidence was produced to support these theories.

Bodian (1952), in his survey of cases purely from the clinical and histological point of view, conceived of the disease as a 'mucosis', or a congenital disorder of mucus production. Shwachman, Leubner and Catzel (1955) measured the viscosity of duodenal fluid obtained by intubation from cases of this disease and found that the fluid was more viscous than fluid from subjects with normal pancreatic function.

Apart from these observations which have been confirmed by others, there has been no evidence recorded to show that the mucin produced by mucus-secreting glands in these cases is any different from that produced by normal subjects. No chemical studies of the mucin in this disease have been reported. Buchanan and Rapoport (1952) made a chemical comparison of normal meconium and meconium from patients with meconium ileus, and decided that the main components of normal meconium were mucopolysaccharides. They found that meconium from a patient with meconium ileus contained less carbohydrate and more nitrogen and that it behaved like a protein in its precipitation reactions. They thought that the persistence of protein in the meconium of an infant with meconium ileus was probably accounted for by the lack of tryptic enzyme secretion into the intestine. The abnormally high viscosity of the abnormal meconium might then be attributed to the fact that frequently mucoproteins exhibit higher viscosities than mucopolysaccharides.

The present study was carried out to see if any difference could be found in the chemical components of mucus from cases of fibrocystic disease of the pancreas and subjects with normal pancreatic function. The study of mucus obtained from the human subject with this disease is beset by the difficulty of obtaining specimens in sufficient quantity and relatively uninfected by organisms.

\section{Material and Methods}

Gastric mucus obtained from post-mortem material was chosen as the only easily available source of material, and also because there had been chemical studies of mucus obtained from this source (Aminoff, Morgan and Watkins, 1950).

The qualitative difference between gastric mucus from eight young children dying with fibrocystic disease of the pancreas and a series of eight young children dying from other disease not involving the pancreas was studied. The mucus was removed from the stomach as soon as possible after death, the stomach being refrigerated until handled.

The fractionation procedure of Smith (1950) for hog gastric mucin was followed. The mucosae were too thin to be separated from the muscle wall by dissection, but the mucous surface was well scraped until all the available mucus was separated. The weight of this material was noted. After the addition of hydrochloric acid it was allowed to autolyse in the presence of toluene at $37^{\circ} \mathrm{C}$. for five days. After filtration and adjustment to $p \mathrm{H} \mathrm{4,}$ 
the mucoid material was separated by precipitation with 5 volumes of cold ethyl alcohol. The precipitate was collected by centrifuging, dissolved in water, and dialysed in cellophane in the cold against daily changes of distilled water for five days. The contents of the dialysis bag was centrifuged to separate out any insoluble material. This was washed, dried and weighed. The solution remaining was again precipitated by alcohol, centrifuged, dried and weighed. Any material in the dialysate was recovered after evaporation of the water on a boiling water-bath and precipitation by alcohol. There were only traces of insoluble and dialysable fractions. The soluble mucin was $0.5 \%$ by weight of the wet mucus removed from the stomach.

In order to determine whether the two pooled purified samples of mucin were identical, an analysis was made of nitrogen content, reducing power and of glucosamine content as was done by Aminoff et al. (1950) on human mucoid substance. The nitrogen estimations were made by the micro-Kjeldahl method. After hydrolysis with $0.5 \mathrm{~N}$ hydrochloric acid at $100^{\circ}$ for 16 hours, the reducing power was estimated by the micro-Somogyi (1937) method, and glucosamine by the method of Elson and Morgan (1933). The data obtained are shown in Tables

TABLE 1

GASTRIC MUCUS FROM CASES OF FIBROCYSTIC DISEASE OF PANCREAS AND CONTROLS

\begin{tabular}{|c|c|c|}
\hline & Controls & $\begin{array}{l}\text { Fibrocystic } \\
\text { Disease of } \\
\text { Pancreas }\end{array}$ \\
\hline 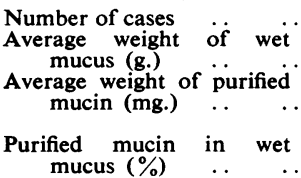 & $\begin{array}{c}8 \\
4 \cdot 3 \\
23 \cdot 1 \\
\text { (range } 2 \cdot 2-48 \cdot 0 \text { ) } \\
0.54\end{array}$ & $\begin{array}{c}8 \\
8 \cdot 7 \\
45 \cdot 9 \\
\text { (range } 16 \cdot 7-72 \cdot 4 \text { ) } \\
0.52\end{array}$ \\
\hline
\end{tabular}

TABLE 2

CHEMICAL COMPOSITION OF POOLED SPECIMENS OF STOMACH MUCIN FROM CASES OF FIBROCYSTIC DISEASE OF PANCREAS AND CONTROLS

\begin{tabular}{|c|c|c|}
\hline & Controls & $\begin{array}{l}\text { Fibrocystic } \\
\text { Disease of } \\
\text { Pancreas }\end{array}$ \\
\hline $\begin{array}{l}\% \text { Nitrogen ... } \\
\% \text { Reducing power as glucose } \\
\% \text { Glucosamine }\end{array}$ & $\begin{array}{l}6 \cdot 82 \\
36 \cdot 3 \\
21 \cdot 5\end{array}$ & $\begin{array}{l}6 \cdot 54 \\
35 \cdot 3 \\
22 \cdot 5\end{array}$ \\
\hline
\end{tabular}

1 and 2. These results are in the range found for partially purified mucin by the earlier workers quoted. It is apparent that the material obtained from cases of fibrocystic disease of the pancreas is the same as that found in other subjects, as far as the estimations made are concerned. The percentage of purified mucin in the wet mucus is the same, and the percentages of nitrogen and reducing power as glucose and glucosamine are almost identical in the two series.

Analysis of the insoluble fractions from both series show the presence of other substances, not mucoid, as impurities. Their reducing power is only of the order of 5 to $6 \%$ and their nitrogen content 7 to $8 \%$. Some of this matter is bacterial in origin as complete filtration by paper is impossible.

\section{Summary}

From the observations of earlier workers it seems likely that in fibrocystic disease of the pancreas there is a difference in the mucus produced in the body. However, at present the evidence rests on histological observations and observation of the physical property of viscosity. The present study indicates that there is no difference with regard to properties as a mucoprotein between mucin obtained from the stomach in children with fibrocystic disease of the pancreas and that of children with normal pancreatic function. The ratio of nitrogen content to reducing power is of the same order. The quantity of mucin in wet mucus also appears similar.

Is it possible that variations in the polymerization of the mucus may be responsible for the differences observed in physical properties?

Our thanks are due to the Pathology Department of the Royal Children's Hospital for cooperation in the collection of material.

\section{REFERENCES}

Aminoff, D., Morgan, W. T. J. and Watkins, W. M. (1950). Biochem. J., 46, 426.

Bodian, M. (1952). Fibrocystic Disease of the Pancreas. London. Buchanan, D. J. and Rapoport, S. (1952). Pediatrics, 9, 304

Elson, L. A. and Morgan, W. T. J. (1933). Biochem. J., 27, 1824.

Farber, S., Shwachman, H. and Maddock, C. L. (1943). J. clin. Invest., 22, 827.

Shwachman, H., Leubner, H. and Catzel, P. (1955). Advanc. Pediat., $7,249$.

Smith, H. (1950). Biochem. J., 46, 356.

Somogyi, M. (1937). J. biol. Chem., 117, 771. 